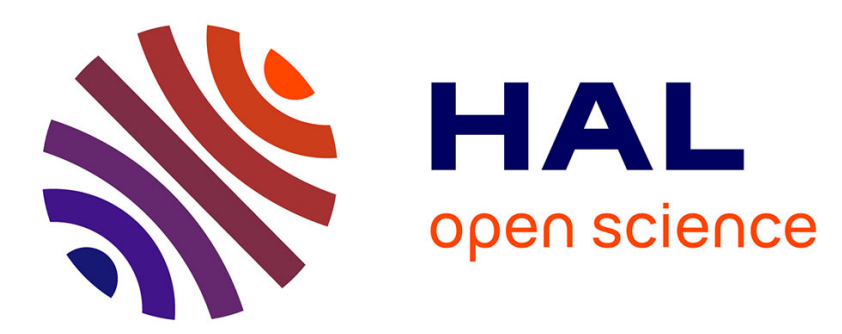

\title{
Experimental and numerical modeling of symmetrical four-branch supercritical cross junction flow
}

\author{
Emmanuel Mignot, André Paquier, Nicolas Riviere
}

\section{To cite this version:}

Emmanuel Mignot, André Paquier, Nicolas Riviere. Experimental and numerical modeling of symmetrical four-branch supercritical cross junction flow. Journal of Hydraulic Research, 2008, 46 (6), pp.723-738. 10.3826/jhr.2008.2961 . hal-00444985

\section{HAL Id: hal-00444985 \\ https://hal.science/hal-00444985}

Submitted on 15 May 2020

HAL is a multi-disciplinary open access archive for the deposit and dissemination of scientific research documents, whether they are published or not. The documents may come from teaching and research institutions in France or abroad, or from public or private research centers.
L'archive ouverte pluridisciplinaire HAL, est destinée au dépôt et à la diffusion de documents scientifiques de niveau recherche, publiés ou non, émanant des établissements d'enseignement et de recherche français ou étrangers, des laboratoires publics ou privés. 


\title{
Experimental and numerical modelling of symmetrical four-branch supercritical cross junction flow
}

\author{
Emmanuel Mignot ${ }^{1}$, André Paquier $^{2}$, Nicolas Rivière ${ }^{3}$
}

\begin{abstract}
During severe urban flooding, the surface flow can become supercritical near some crossroads if the slope of the streets reaches a critical steepness. The present study aims to validate the capacity of a code solving the two-dimensional shallow water equations to simulate the flows in a fourbranch supercritical cross junction. An experimental study showed that five main flow patterns can be observed and are determined by the upstream flow characteristics as well as the slope of the channels. Computed and measured flows were compared on five detailed water depth fields and on more than 200 measured flow rate distributions. It appears that the flow rate distribution to the downstream branches and the flow characteristics, computed by the code using a set of reference parameters, compare well with the experimental data. Nevertheless, some discrepancies appear concerning the prediction of the location and of the thickness of the oblique jumps mainly because jumps are set on one cell in the numerical model. Furthermore, the flow patterns remains well predicted when altering the set of numerical parameters though the water depth field is slightly modified when changing the friction coefficients or the other parameters governing energy losses.
\end{abstract}

\section{Keywords}

Junction, Supercritical flow, Experimental study, 2D shallow water equations, Numerical validation

\footnotetext{
${ }^{1}$ PhD student, Cemagref, Hydrology - Hydraulics Research Unit, 3 bis, quai Chauveau, CP 220, 69336 Lyon Cedex 09, France 


\section{Introduction}

Junction flows occur in various natural or artificial network systems. Most junctions can be found in irrigation, drainage, watersheds and sewer systems where the flow is primarily subcritical. Consequently, most of the studies on junction flow deal with subcritical flows. However, during urban flooding, junction flows can also be encountered in street networks where the flow regime is usually subcritical but can also be supercritical if the slopes of the streets and the flow rates are high enough (Mignot et al., 2006a). In most cities, three and four branch junctions dominate the configurations of street junctions.

Detailed descriptions of the flow characteristics in the vicinity of the three-branch junctions in subcritical conditions can be found in experimental studies such as Best and Reid (1984), Weber et al. (2001) for confluences and Neary et al. (1999) for bifurcations. The main flow structures considered in these papers are the areas with recirculating flows, induced secondary circulation, shear separation planes and flow contraction.

Concerning three-branch supercritical junctions, Bowers (1966) showed that for a confluence, a hydraulic jump can develop within the upstream channels of the junction depending on the geometry of the junction and the upstream flow rates. Furthermore, the author states that the position of the jump is dependent upon the discharge of the joining channels and when a jump does not form, waves are created at the junction. Behlke and Pritchett (1966) studied the location and characteristics of diagonal waves occurring in such flows. Rice (1985) used an experimental device to explore the influence of several flow characteristics and geometrical parameters on the location of the hydraulic jumps. Hager (1989) described a three branch supercritical flow junction in which both upstream flows deflect suddenly once reaching the oblique wave front. Schwalt and Hager (1995) provided the main features of the waves forming at the junction of two supercritical flows with a low junction angle. Finally, Rivière and Perkins (2004) gave a description of a right angle supercritical flow division.

Nania et al. (2004) presented a description of the supercritical flow patterns occurring at a right angle junction with two upstream and two downstream channels. The authors divided the observed flow patterns into two types depending on the location of the hydraulic jumps: Type I for which two jumps are formed in the input channels and Type II for which one jump is formed in one input channel and the other is formed in the crossing.

In terms of numerical computation, Shettar and Murthy (1996) simulated a subcritical threebranch bifurcation using a two-dimensional (2D) model that solves the shallow water equations completed by a $k$ - $\varepsilon$ turbulence closure. The computed flow appeared to be in fair agreement with their experimental data and those of former studies. Then Khan et al. (2000) applied 2D shallow water equations with a simpler turbulence model based on the formulation of mixing length to 
compute the flow patterns that appear at three-branch subcritical bifurcation and confluence and validated their model using previous experimental data. Both 2D numerical models provided a fair estimate of main flow characteristics such as the flow distribution in the downstream branches, the depth-averaged velocities and the dimensions of the recirculation zone though some discrepancies existed concerning the average velocity distribution in the lateral downstream branch. Finally, Huang et al. (2002) used a 3D model with a k- $\varepsilon$ turbulence closure scheme to simulate Shumate and Weber (1998)'s experimental data of a junction flow. However, all these studies concerned junction flows in subcritical regimes; for supercritical junction flow, to the authors' knowledge, no validation of 2D or 3D model is available in the literature. This statement is odd considering that an increasing number of urban flood studies (such as Calenda et al., 2003; Ishigaki et al., 2004; Schmitt et al., 2004) apply 2D shallow water equation models to simulate the street network in which the flow can become supercritical at the flood peak (Mignot et al., 2006a).

The present paper proposes to study the capacities of a $2 \mathrm{D}$ shallow water equation model with a simple turbulence closure scheme to simulate experimental supercritical four-branch junction flow configurations. First, the equations and the numerical scheme are presented. The second section describes the experimental set-up and the main flow patterns. The third section compares measurements and calculation results for the flow rate distribution in the downstream branches of the junction for three slope configurations and the water depths for some cases corresponding to the flow patterns observed experimentally. Finally, the influence of the main numerical parameters on the computed flow features is investigated.

\section{The governing equations and the numerical scheme}

The code Rubar20 was used for the calculations. It solves the 2D shallow water equations. The 3 equations are the continuity equation (1) and two equations for the conservation of momentum in both orthogonal plane directions (2) and (3):

$$
\begin{gathered}
\frac{\partial h}{\partial t}+\frac{\partial(h u)}{\partial x}+\frac{\partial(h v)}{\partial y}=0 \\
\frac{\partial(h u)}{\partial t}+\frac{\partial\left(h u^{2}\right)}{\partial x}+\frac{\partial(h u v)}{\partial y}+g h \frac{\partial h}{\partial x}=-g h \frac{\partial z_{b}}{\partial x}-g \frac{u \sqrt{u^{2}+v^{2}}}{K_{s}^{2} h^{1 / 3}}+v \frac{\partial}{\partial x}\left(h \frac{\partial u}{\partial x}\right)+v \frac{\partial}{\partial y}\left(h \frac{\partial u}{\partial y}\right) \\
\frac{\partial(h v)}{\partial t}+\frac{\partial(h u v)}{\partial x}+\frac{\partial\left(h v^{2}\right)}{\partial y}+g h \frac{\partial h}{\partial y}=-g h \frac{\partial z_{b}}{\partial y}-g \frac{v \sqrt{u^{2}+v^{2}}}{K_{s}^{2} h^{1 / 3}}+v \frac{\partial}{\partial x}\left(h \frac{\partial}{\partial x}\right)+v \frac{\partial}{\partial y}\left(h \frac{\partial v}{\partial y}\right)
\end{gathered}
$$

in which $h$ is the water depth, $u$ and $v$ are the velocity components along horizontal $x$ and $y$-axis, $z_{b}$ is the bottom elevation, $K_{s}$ is the Strickler roughness coefficient $\left(K_{s}=1 / n\right.$ with $n$ the Manning 
coefficient), $g$ is the gravitational acceleration and $v$ the diffusion coefficient. In most of the calculations, it was assumed that the diffusion coefficient $v$ is constant throughout the flow field. However, the model defined by the following relation was also tested:

$$
v=k h u^{*}
$$

in which $k$ is a dimensionless coefficient and $u^{*}$ the bottom friction velocity that can be approximated by the usual relation involving the friction coefficient (5) or a relation involving the variations of the water surface elevation (6).

$$
\begin{gathered}
u^{*}=\sqrt{g \frac{u^{2}+v^{2}}{h^{1 / 3} K_{s}^{2}}} \\
u^{*}=\sqrt{g h \sqrt{\left(\frac{\partial\left(z b^{+h}\right)}{\partial x}\right)^{2}+\left(\frac{\partial(z b+h)}{\partial y}\right)^{2}}}
\end{gathered}
$$

The conservative form of Eqs. (1) to (3) are solved on a regular grid constituted of quadrilaterals using an explicit second-order numerical scheme that is adapted from MUSCL approach (VanLeer B., 1979). The scheme includes four steps:

1. Compute the slope of each one of the three variables $z=z_{b}+h, h u$ and $h v$ in every cell along the $x$ and $y$ axis by the least squares method and apply limitations of slopes of minmod Van Leer type in order to obtain a Total Variation Diminishing (TVD) scheme.

2. Compute values of $W=(h, h u, h v)$ at intermediate time $t_{n+1 / 2}=t_{n}+0.5^{*} \Delta t$ in the middle of the edge $m_{i j}$ of cell $M_{i}$ (common with cell $M_{j}$ ) to obtain a second-order scheme with

$$
W_{m_{i j} L}^{n+1 / 2}=W_{m_{i j} L}^{n}-0.5 \Delta t\left[\frac{\partial f_{1}}{\partial W}\left(W_{i}^{n}\right) \cdot W_{x i}^{n}+\frac{\partial f_{2}}{\partial W}\left(W_{i}^{n}\right) \cdot W_{y i}^{n}\right]+0.5 S_{i}^{n} \Delta t
$$

in which $f_{1}$ and $f_{2}$ are the fluxes along $x$ and $y$ axis respectively, corresponding to the first member of Eqs. (1), (2) and (3) (which means, for instance, $f_{1}=\left(u, \frac{u^{2}}{h}+g \frac{h^{2}}{2}, \frac{u v}{h}\right)$ ), $S$ is the second member of these equations, $W_{x i}^{n}$ and $W_{y i}^{n}$ are the slopes of $W$ along $x$-axis and $y$-axis respectively at time $t_{n}$, index $L$ and $R$ indicate the left and right side of the edge (i.e. cell $M_{i}$ and $M_{j}$ respectively), and $\Delta t$ the time step.

3. Solve a 1D Riemann problem (Roe, 1981) at $t_{n+1 / 2}$ in the direction normal to the edge (Eq. 8) similar to Eqs. (1)-(2)-(3) without second member $S$ on $x$-axis (as these last equations do not vary through a rotation) in order to estimate the fluxes through edges for the conservative part of the equations. It is possible to use a Roe type linearization that directly provides an estimate of the fluxes. 


$$
\left\{\begin{array}{c}
\frac{\partial W}{\partial t}+\frac{\partial}{\partial x}\left(f_{l}(W)\right)=0 \\
W\left(x, t_{n+1 / 2}\right)=W_{m_{i j} L}^{n+1 / 2} \text { if } x<0 \\
W\left(x, t_{n+1 / 2}\right)=W_{m_{i j} R}^{n+l / 2} \text { if } x>0
\end{array}\right.
$$

4. Integrate the terms of the second member $S$ of the set of Eqs. (1) to (3) on the surface of the cell and add this second member at intermediate time $S_{i}^{n+1 / 2}$ in order to obtain the final value of the solution in cell $M_{i}$ at time $t_{n+1} W_{i}^{n+1}$ with:

$$
W_{i}^{n+1}=W_{i}^{n}+\sum_{j} \frac{\varepsilon_{i j} l_{i j}}{A_{i}} \Delta t f_{1}\left(W_{m_{i j}}^{n+1 / 2}\right)+S_{i}^{n+1 / 2} \Delta t
$$

summing on the $j$ cells that have a common edge with cell $M_{i}$ (of area $A_{i}$ ) with $\varepsilon_{i j}$ equal to 1 or -1 according to the orientation of edge $m_{i j}$ (length $l_{i j}$ ), common to cells $M_{i}$ and $M_{j}$.

The contribution of the second member $S$ includes:

* Gravity or slope terms $\left(-g h \partial_{b} / \partial x\right.$ or $\left.-g h \partial_{z_{b}} / \partial y\right)$ treated as fluxes in such a way as a horizontal water surface remains strictly horizontal if no additional volume is considered.

* Bottom friction terms that are simply assessed at the centre of the cells. Their computation uses an implicitation in time in order to avoid numerical instabilities when a rapid change in the water depth or velocity occurs. If the flow is locally fully rough, as in most natural situations, the Strickler coefficient $K_{s}$ does not depend on the Reynolds number $R_{e}$ and is considered constant in time and space as long as the flow can be considered as shallow. Then, the $K_{s}$ value only depends on the bottom material. On the other hand, if the flow is hydraulically turbulent smooth or at the transition between the smooth and rough zone, the local Strickler coefficient depends on the local flow characteristics: water depth and average velocity. In such case, the corresponding Strickler coefficient varies between cells and with time if the flow is unsteady and therefore has to be computed in each cell at each time step using Eq. (10)

$$
K_{s}=\sqrt{\frac{8 g}{h^{1 / 3} f}}
$$

in which $h$ replaces the hydraulic radius in the traditional expression of $K_{s}, g$ the acceleration of gravity and $f$ the Darcy-Weisbach friction factor which is usually computed using ColebrookWhite equation (French, 1985). However, if the local flow is at the transition between a fully rough flow and a hydraulically smooth turbulent flow according to the modified Moody diagram (French, 1985), Eq. (11) from (Yen, 2002) can be used to compute the friction factor $f$ explicitly

$$
f=\frac{1}{4}\left[-\log \left(\frac{k_{s}}{12 h}+\frac{6.79}{R_{e}^{0.9}}\right)\right]^{-2}
$$


in which $R_{e}$ is the Reynolds coefficient: $R_{e}=4 U h / v_{k}$ with $v_{k}$ the kinematic viscosity coefficient, $k_{s}$ is a length parameter which characterises the roughness of the material (French, 1985), $U$ is the local average velocity and $h$ is the water depth that replaces the local hydraulic radius of the original equation.

* Diffusion terms computed as fluxes from the gradient of the velocities, which means that, for instance, the term $\frac{\partial}{\partial x}\left(h \frac{\partial u}{\partial x}\right)$ is replaced in the cell $M_{i}$ by $\frac{\partial}{\partial x}\left(h u_{x i}^{n}\right)$.

The numerical scheme can compute highly unsteady flows and treat the transitions between subcritical and supercritical flows as ordinary points (Paquier, 1995). Drying and wetting of cells are treated specifically in the following way: a cell is considered to remain dry as long as the water volume entering it during one time step provides an average cell water depth $h$ lower than a minimum value (i.e. $0.01 \mu \mathrm{m}$ in the present case). During the drying process, a similar option is used and leads to a mass conservation error that is usually less than $0.01 \%$ of the total mass. This numerical scheme is stable if the value of the terms within the second member in Eqs. (2) and (3) remain low and if the Courant number is limited to values below unity, which is the Courant Friedrichs Levy condition.

The validation of the numerical scheme against analytical solutions and experimental data sets in supercritical flow situations was performed in the IAHR group on dam-break wave, in collaborative research with the University of Kyoto and during the CADAM (Soares Frazao et al., 2000) and IMPACT (Morris, 2005) European research projects that included comparisons with other European numerical codes. Some of these experiments include dam break wave calculations in simple rectangular channels (Paquier, 2001), on more irregular topographical domains with the introduction of blocks to simulate obstacles (Mignot and Paquier, 2003a; Mignot and Paquier, 2003b) or on a town physical model simulating an urban flood situation (Mignot et al., 2006b). All these tests proved both the accuracy of this code for solving 2D shallow water equations under rapid flow conditions and complex topographical situations and the importance of choosing the adapted numerical parameters to simulate a supercritical flow with accuracy.

\section{Experimental investigation}

\section{Experimental set-up and measuring techniques}

The experiments, presented with more details in (Mignot et al., 2008), were performed in four identical rectangular channels, made of glass, of length $L_{c}=2 \mathrm{~m}$ and of width $b=0.3 \mathrm{~m}$ that were joined at 90 degrees (Figure 1). The coordinate system was defined as shown in Figure 1. $S_{x}$ and $S_{y}$ parameters represent the slopes of the $x$-axis and $y$-axis channels respectively. These slopes - 
adjustable between $\pm 5 \%$ - were set such that $S_{x}=S_{y}$ but the square junction remained horizontal. The water entered both perpendicular inlet channels through honeycomb screens and a sluice gate was used to set the normal depth $h_{n}$ at the upstream end of the inlets. The maximum input discharge was 10 litres per second (1/s). The corresponding Reynolds number varied between $1.2 \times 10^{4}$ and $7 \times 10^{4}$ depending on the channel slope. $h_{n}$ was derived from a Darcy friction coefficient related to smooth glass surfaces and in all the experiments, $h_{n}$ never exceeded $3 \mathrm{~cm}$. Therefore, the ratio of channel length to flow depth $\left(L_{c} / h\right)$ was in the range $50 \leq L_{c} / h \leq 100$, which was sufficient to ensure a fully developed flow in the measurement region, at least, in the absence of any disturbance generated by the intersection (Ranga Raju et al., 2000).

The discharges at the inlets and the outlets were measured by four identical electromagnetic flowmeters (Promag 50 from Endress Hauser; accuracy: $\pm 0.021 / \mathrm{s}$ ). When the four discharges values were stable with a zero mass balance, the flow was considered to be steady and the measurements were collated. In regions of uniform flow, the water depth was measured with a moveable point gauge with an accuracy of $\pm 0.15 \mathrm{~mm}$. Such a device can only be used in zones of low disturbance. Where the flow was strongly disturbed (for instance, near eddying zones or hydraulic jumps), a moveable wave probe (Wave Monitor from Churchill Inst.) was used. The gap between the two wires composing the probe was $1 \mathrm{~cm}$ and the horizontal position of the gauge was measured with a $\pm 1 \mathrm{~mm}$ accuracy. The accuracy of the water level measurements was affected by various uncertainties due to wetting process, wake formation and vertical positioning of the probe: in these experiments, it was estimated to be $\pm 0.5 \mathrm{~mm}$. The oblique jump angle was obtained by measuring the location of the intersection between the oblique jump and the upstream end of the output channels and applying basic geometric relationships. Due to the width of the jump, the uncertainty concerning the angle measurement was estimated equal to $\pm 2.5^{\circ}$. Finally, the location of the normal jump in the upstream branches was obtained by measuring the distance between the jump and the junction with an uncertainty of about $\pm 2 \mathrm{~cm}$ due to the oscillations of the jump.

\section{Main flow description}

The experimental configurations described in this paper were obtained by setting the branch slopes $S_{x}$ and $S_{y}$ to $1 \%, 3 \%$ and 5\%, ranging the flow rates between 0 and $10 \mathrm{l} / \mathrm{s}$ and considering that the upstream discharge in the $x$-direction was higher than the upstream discharge in the $y$ direction: $Q_{e x}>Q_{e y}$. Both flows were uniform and supercritical when entering the channels, however due to the intersection, the flows were deflected and two hydraulic jumps appeared. Each hydraulic jump was either normal and located within an upstream branch, or oblique and 
confined in the junction. Three main flow types could be observed experimentally (Mignot et al., 2008) and the transition between them was essentially based on the characteristics of the hydraulic jumps.

Type I corresponded to a configuration with one normal hydraulic jump in each upstream branch. Both upstream flows reached the junction entry sections under subcritical conditions and returned to supercritical conditions in the downstream branches. This flow type was observed for quite symmetrical flow configurations with slopes of $1 \%$.

Type II occurred when there was a high difference in the upstream flow rates between both upstream branches. A normal hydraulic jump appeared within the upstream minor flow channel and an oblique jump appeared within the junction. Then, the main flow reached the junction under supercritical conditions while the minor flow reached the junction under subcritical conditions. This flow type was subdivided by (Mignot et al., 2008) into three "regimes" depending on the position of the oblique jump with respect to the downstream cross corner, thus leading to various flow distribution structures. Type II regime 1 referred to an oblique jump angle much lower than $45^{\circ}$ in such a way that the oblique jump and the depression wave did not intersect (Figure 2a). Type II regime 2 corresponded to an oblique jump angle slightly lower than $45^{\circ}$ in such a way that the oblique jump intersected the depression wave inside the square junction (Figure 2b). For these two flow regimes, the flow distribution was mainly governed by the depression wave because the downstream lateral flow (in the $y$-direction) originated from this wave in the form of a lateral jet development (Rivière and Perkins, 2004). Type II regime 3 corresponded to an oblique jump angle higher than $45^{\circ}$ and the flow distribution was highly dependent on this angle because in this case the oblique jump was responsible for the deflection of the upstream main flow (Figure 2c).

Finally, Type III corresponded to a configuration with two oblique jumps within the junction. Hence, both upstream flows reached the junction under supercritical conditions and were deflected when crossing the oblique jumps (Figure 2d). Such flow types were only observed for the $5 \%$ slope configuration.

Furthermore, the transition between flow types was not sudden and therefore some intermediate flow configurations between two flow types could occur when at least one hydraulic jump was in transition between an oblique jump held in the square junction and a normal jump detached in an upstream branch. For instance, if both hydraulic jumps were transitional, the observed flow was intermediate between a Type I and a Type III flow (Figure 2e).

The flow type was ruled by four dimensionless parameters (Rivière et al., 2005) that were the two upstream Froude numbers $F_{r x}, F_{r y}$, the upstream discharge ratio $\left(Q_{e x} / Q_{T}\right)$ and the dimensionless main upstream discharge $Q_{e x} /\left(b^{5 / 2} g^{1 / 2}\right)$. Indeed, the locations and the types of 
observed hydraulic jumps depended on the ability of the two upstream flows to deviate from their original direction through an oblique jump. For the two upstream flows, the maximum deviation allowed by an oblique jump depended on the Froude numbers $F_{r x}$ and $F_{r y}$ (Ippen, 1951) while the deviation imposed by one flow to the other one depended on the upstream discharge ratio $\left(Q_{e x} / Q_{T}\right)$ and the dimensionless main upstream discharge $Q_{e x} /\left(b^{5 / 2} g^{1 / 2}\right)$. The respective influences of the four parameters were similar (Rivière et al., 2005). Due to experimental restrictions, the slopes were fixed instead of the Froude numbers. Table 1 provides the corresponding range of upstream discharge ratio $\left(Q_{e x} / Q_{T}\right)$ and upstream Froude numbers $\left(F_{r x}\right.$ and $\left.F_{r y}\right)$ for the various flow types met in the experimental configurations; the dimensionless main upstream discharge $Q_{e x} /\left(b^{5 / 2} g^{1 / 2}\right)$ varied generally from $6.510^{-3}$ to $6.510^{-2}$.

\section{Measurements}

Three kinds of measurements were collected experimentally.

* First, 63 oblique jump angles $\beta$ at 5\% slopes and 80 normal hydraulic jump locations (37 at 5\% slopes and 43 at $1 \%$ slopes) were measured.

* Secondly, the discharges in the four branches were measured for 209 configurations (see Table 2 for the distribution).

* Finally, the water depth field for five specific flow configurations relative to the main flow patterns reported were acquired experimentally with about 250 measurement points in the junction (Table 3). It can be noted that no water depth field of Type I flow was recorded since the flow within the junction was fully subcritical in this case and should be well predicted by the code according to the literature review.

\section{Comparison of measurements and reference calculation results}

Comparison of measured and computed angles of oblique jumps and locations of normal jumps As a first step, each flow configuration from Table 2 is computed using the Rubar20 code and the set of reference parameters described in the sequel.

For all the configurations, the flow at the junction is in transition between a fully rough flow and a smooth turbulent flow. The friction coefficient at the bottom of the channel depends on the bottom roughness but also on the local flow characteristics. Consequently, the Strickler coefficient $K_{s}$ is computed at each time step in each cell using Eqs. (10) and (11). The diffusion coefficient is set to 0 . The mesh, referenced $M 3$ in Table 4, is regular; each cell is a square with a typical length of $3 \mathrm{~cm}$ (Figure 3 ). The mesh comprises 10 cells per channel section and 100 cells within the square junction. The upstream boundary conditions are both upstream discharges and corresponding normal water depths. The two downstream boundary conditions are free flow and 
it was verified that the boundary condition election had no influence on the flow within the junction. The computation lasts until the flow becomes stabilized.

Mignot (2005) showed the importance of the location of the jumps and particularly the oblique jump angle to estimate the flow rate distribution in configurations of Type II and Type III. Figure 4 shows that the angle $\beta$ is predicted with relative accuracy both for Type II and Type III flows, though this angle is overestimated for low angles $\left(<45^{\circ}\right.$ which corresponds to Type II regimes 1 and 2) and underestimated for high angles $\left(>50^{\circ}\right)$ in Type III compared to experimental measurements.

Furthermore, concerning the normal jump located in the minor upstream branch for 5\% slopes configurations, it appears that its distance from the junction is overestimated when this distance is lower than $17 \mathrm{~cm}$ and is underestimated for normal jumps located further from the junction (Figure 5). On the other hand, for the $1 \%$ slopes configurations, the distance between the computed normal jumps and the junction is predicted with greater accuracy though it appears to be underestimated by about $15 \mathrm{~cm}$ for most configurations (Figure 6).

\section{Comparison of flow rate distribution in the downstream branches}

In order to evaluate the capacity of the numerical code to predict the flow rate distribution at the junction, a quality indicator $\left(E_{Q T}\right)$ is used:

- $\quad E_{Q T}=\left(\frac{Q_{s x C}-Q_{s x M}}{Q_{T}}\right)=\left(\frac{Q_{s y M}-Q_{s y C}}{Q_{T}}\right)$ in which $Q_{s x C}$ and $Q_{s x M}$ are the computed and measured downstream flow rate along the $x$-axis and $Q_{T}$ is the sum of the upstream flow rate $\left(Q_{T}=Q_{e x}+Q_{e y}\right)$.

- $A b s\left(E_{Q T}\right)$ is the absolute value of $E_{Q T}$ and $\overline{A b s\left(E_{Q T}\right)}=\Sigma\left[A b s\left(E_{Q T}\right)\right] / n_{b}$ with $n_{b}$ the number of studied configurations.

\section{Slope configurations of $S_{x}=S_{y}=5 \%$}

The prediction of the flow rate distribution in the downstream branches of the junction using the 2D numerical code is compared to the measured flow distribution in Figure 7. It appears that the major downstream flow rate $\left(Q_{s x}\right)$ is overestimated for all flow types $\left(E_{Q T}>0\right)$. Nevertheless, this overestimate is limited to about $1 \%$ for Type II regimes 1 and 2 in which the lateral jet development governs the flow distribution (Mignot, 2005). Concerning Type III configurations, slight underestimation of the oblique jump angle $\beta$ presented above is responsible for the underestimate of the deflected flow rate from $Q_{e x}$ to $Q_{s y}$ and thus for the overestimate of $Q_{s x}$ or $E_{Q T}$ (see Figure 8 or Table 5).

\section{Slope configurations of $S_{x}=S_{y}=3 \%$}


The flow type that occurs at configurations close to the symmetry $\left(Q_{e x} Q_{e y}\right)$ is intermediate between a Type I and Type III with two transitional hydraulic jumps between a normal jump and an oblique jump (Figure 2e). In such a case, the flow distribution is fairly predicted by the numerical code (Figure 9). For higher $Q_{e x}$ discharge, the calculation tends to underestimate $Q_{s x}$ (and then $E_{Q T}$, see Table 5) for Type II regime 3 flow patterns, while it computes $Q_{s x}$ with fair agreement in Type II regimes 1 and 2. Explanations are similar to 5\% slope configurations.

\section{Slope configurations of $S_{x}=S_{\underline{y}}=1 \%$}

For these configurations in Type I, the main outlet discharge $Q_{s x}$ is underestimated by about $2 \%$, meaning that the numerical code tends to homogenize the flow distribution at the junction more than it actually occurs (Figure 10). In a Type II regime 3, $Q_{s x}$ is overestimated, unlike the case of slopes equal to 3\% (Figure 9) or 5\% (Figure 7).

Consequently, $\overline{A b s\left(E_{Q T}\right)}$ appears to be quite high (3\% to 5\%) for the flow types in which the oblique jump angle governs the flow distribution between the downstream branches of the junction (i.e. Type II regime 3 and Type III) and is lower in Type I (1\% to $2 \%$ ) in which no oblique jump occurs and in Type II regimes 1 and $2\left(\overline{A b s\left(E_{Q T}\right)}<2 \%\right)$ in which the oblique jump does not influence the flow distribution (see Table 5).

\section{Comparison between experimental and computed water depth fields}

Concerning the configurations from Table 3, the 2D code computes the local water depths at the centre of each cell. Then, these water depths are interpolated on a fine regular grid of typical length equal to $1 \mathrm{~mm}$ and plotted with water depth isolines at constant grey level intervals. Similar procedure is performed for the experimental flow in order to qualitatively compare the water depth fields in the junction.

The water depth fields computed using the set of reference parameters agree with the five water depth fields measured on the experimental model (Figure 11): all the hydraulic structures such as the oblique or normal jumps, the eddying, and the recirculation zones are predicted by the numerical code at a location close to the measurements. Such statement is confirmed by the comparison of the computed and measured water depth profiles at the centre of the channel along the x-direction (for instance, $C_{21}$ configuration in Figure 12).

However, when looking more precisely at the details of the flow structures, some discrepancies can be found between computed and measured water depth fields. The flow structure at the centre of the junction for the configuration $C_{l}$ is simplified by the numerical code. Moreover, the shape and location of the normal hydraulic jump in the minor upstream branch $Q_{e y}$ are not perfectly estimated for $C_{21}, C_{22}$ and $C_{3}$ configurations. Also, some discrepancies exist in terms of the shape or location of the eddying for $C_{22}$ and $C_{23}$ configurations (Figure 11). Finally, the computed 
oblique jumps differ from the measured ones. In experiments, for high oblique jump angles configurations $\left(C_{1}, C_{23}\right.$ and $\left.C_{3}\right)$, the oblique jump is thicker than for low oblique jump angle configurations $\left(C_{21}\right)$. However, the transition from supercritical to subcritical flows predicted by the numerical scheme extends to one cell (i.e. $3 \mathrm{~cm}$ in the present mesh M3). Consequently, the oblique jump thickness is underestimated by the code for the configurations with high $\beta$ and overestimated for the low $\beta$ angle configurations.

In order to test the accuracy of the code using the set of reference parameters in predicting the local flow depths at the junction, a more detailed comparison of the measured and computed water depths is presented hereafter. First, for each flow configuration from Table 3, the computed water depths obtained at the centre of the 100 numerical cells of the junction are interpolated over the experimental set of measurement points located in the junction allowing to directly compare the measured and computed water depths at the same coordinate locations. The computational error $d h\left(d h=h_{C}-h_{M}\right)$ is calculated at each measurement point and the average error $\overline{d h}$ and the root mean square error $\varepsilon$ are obtained using $\overline{d h}=\Sigma(d h) / n_{b}$ in which $n_{b}$ is the number of water depth measurements in the junction and $\varepsilon=\sqrt{\sum\left[(d h)^{2}\right] n_{b}}$.

These statistical values are presented in the second column of Table 11 corresponding to the set of reference parameters ( $K_{s}$ obtained from Eqs. (10) and (11) and mesh M3). The local water depths are estimated with an average error $\overline{d h}$ of about $1 \mathrm{~mm}$ (except for $C_{3}$ case) with a typical root mean square error $\varepsilon$ of 3 to $12 \mathrm{~mm}$. Moreover, $\overline{d h}$ is positive indicating that the water depth field is globally overestimated for all the configurations especially for the configurations $C_{22}$ and $C_{3}$. Concerning the $C_{22}$ flow configuration, the reason is that the eddying around the stagnation point is predicted in the vicinity of the downstream corner of the junction while experimentally, this increase in water depth is located within the ' $y$ ' downstream branch of the junction, thus out of the area of comparison. On the other hand, the overestimation of the $C_{3}$ water depths is related to the underestimation of the computed oblique jumps thickness. Consequently, though the location of the feet of the jumps are well predicted, the increase in water depth through the computed oblique jumps is too steep and locally creates excessively high water depths. The same phenomenon can be observed for $C_{23}$ that is also a thick oblique jump configuration but, in this case, the water depth overestimate is compensated by an underestimate of the high water depths near the upstream corner of the junction. 


\section{Influence of some numerical parameters}

The objective of the following paragraph is to study the influence of the main numerical parameters on the computed flows. For each parameter considered, a description of the modified numerical configuration is provided with the consequences in terms of qualitative and quantitative changes on the computed flow structures and water depth fields.

\section{Influence of a constant friction coefficient}

As stated before, the flow is intermediate between turbulent smooth and rough and Eqs. (10) and (11) are applied to compute the local Strickler coefficient. The average equivalent Strickler coefficient in the upstream branches and the junction obtained from the flow characteristics computed in the previous paragraph when using Eqs. (10) and (11) are presented in Table 6. This coefficient stands between 103 and $105 \mathrm{~m}^{1 / 3} \cdot \mathrm{s}^{-1}$ in the junction (except for $C_{21}$ ) and between 116 and $118 \mathrm{~m}^{1 / 3} \cdot \mathrm{s}^{-1}$ in the upstream branches. Then, two constant friction factors were tested: $K_{s}=100$ $m^{1 / 3} \cdot s^{-1}$ and $K_{s}=115 m^{1 / 3} \cdot s^{-1}$ while keeping the reference values for the other numerical parameters and mesh characteristics.

The flow pattern computed for the $C_{23}$ configuration is quite similar using the reference friction coefficient equations and both constant friction coefficients (Figure 13). However, it appears that the flow structures computed with $K_{s}$ from Eqs. (10) and (11) are closer to the flow structures computed with $K_{s}=115 \mathrm{~m}^{1 / 3} \cdot \mathrm{s}^{-1}$ than with $K_{s}=100 \mathrm{~m}^{1 / 3} \cdot \mathrm{s}^{-1}$. Furthermore, the main modification in terms of flow patterns for the 5 configurations from Table 3 when using $K_{s}=100 \mathrm{~m}^{1 / 3} \cdot \mathrm{s}^{-1}$ occurs in $C_{21}$ (Figure 14) for which the computed normal hydraulic jump is perpendicular to the upstream branch axis unlike using the set of reference parameters (see Figure 11).

For a quantitative comparison, the average error $(\overline{d h})$ and the root mean square error $(\varepsilon)$ between the water depth fields computed in the junction with the three friction relations are shown in Table 7. These results confirm that the flows computed with a constant $K_{s}$ value of $115 \mathrm{~m}^{1 / 3} \cdot \mathrm{s}^{-1}$ are closer to the flow patterns derived by Eqs. (10) and (11) than when using a $K_{s}$ value of 100 $\mathrm{m}^{1 / 3} \cdot \mathrm{s}^{-1}$. However, neither calculation permits to improve the computed water depth results at the junction (Table 11) and the discharge distribution in the downstream channels (Table 8) except for $K_{s}=100 \mathrm{~m}^{1 / 3} \cdot \mathrm{s}^{-1}$ in Type I in which the subcritical flow in the junction governs the discharge distribution.

In the following text, a constant Strickler coefficient $K_{s}=115 \mathrm{~m}^{1 / 3} \cdot \mathrm{s}^{-1}$ will be used, considering the similarity of the computed flows with the ones computed using the reference set of parameters.

\section{Influence of changing the mesh density}


The objective of this test is to check the influence of four regular mesh densities with square cells, the dimensions of which are $0.5,1,3$ and $10 \mathrm{~cm}$ for respectively the M1, M2, M3 and M4 grids (Table 4). The five flow configurations from Table 3 are thus calculated with the three new meshes and results are interpolated on a $1 \mathrm{~mm}$ grid as for the reference calculation. The $C_{23}$ computed flow patterns are presented in Figure 15. It appears that the four flow patterns are quite similar and in fair agreement with the measured flow patterns. Indeed, the various flow structures (oblique jump, normal jump, eddying) are predicted at the same locations as in the experimental measurements. However, the flow pattern computed using the coarser mesh (M4) comprising only nine cells in the junction is highly simplified. Moreover, using this mesh density, both the oblique jump and the normal jump appear thicker than with the reference mesh (M3) and for the experimental measurements while the thickness of the jumps are narrower with the denser meshes (M1 and M2) as the thickness of the computed jumps equals one space step. Finally, as the space step $(3 \mathrm{~cm})$ is close to the thickness of the oblique jump, the mesh density $M 3$ permits to get the lowest root mean square error $(\varepsilon)$ with regard to the measured water depth field, the mean error $(\overline{d h})$ being similar as for $M 1, M 2$ and $M 4$ (Table 11$)$.

\section{Influence of changing the longitudinal mesh density in the branches}

We check the influence of reducing the longitudinal mesh density in the inlet and outlet branches of the junction on the predicted flow patterns. The cells dimensions are increased to $30 \mathrm{~cm}$ in the direction of the axes of the branches and remain unchanged $(3 \mathrm{~cm})$ in the perpendicular direction. Consequently, at the junction, the new mesh (named "longi") remains similar to the M3 mesh. The main modifications in the flow patterns are:

- The flow is simplified within the upstream and downstream branches.

- The normal jump in the minor upstream branch of $y$-direction is drastically smoothened: its length passes from 3 to $30 \mathrm{~cm}$ (the longitudinal dimension of a cell), which tends to modify the flow characteristics at the entry section of the junction (see Figure 16) and thus to affect the flow pattern within the junction, particularly, the angle of the oblique jump and the location of the eddying.

- Table 9 shows that the differences in terms of water depth fields in the junction are high, the results are less accurate with this longer longitudinal mesh density in the branches than when using $M 3$ regular mesh (Table 11).

\section{Influence of taking into account a diffusion coefficient}


The objective is to evaluate the effects of considering the three following methods to compute the diffusion coefficient $v$ used in Eqs. (2) and (3), with mesh density $M 3$ and the constant friction coefficient $K_{s}=115 \mathrm{~m}^{1 / 3} \cdot \mathrm{s}^{-1}$.

(a) A constant diffusion coefficient $v=0.01 \mathrm{~m}^{2} \mathrm{~s}^{-1}$.

(b) A diffusion coefficient $v$ derived from Eqs. (4) and (5) with a $k$ factor equal to 0.1.

(c) A diffusion coefficient $v$ derived from Eqs. (4) and (6) with a $k$ factor equal to 0.1.

Figure 17 shows the $C_{23}$ flow patterns computed with the three former relationships and Table 10 shows the comparison between the computed water depth fields and the reference calculation fields. The modifications are limited both qualitatively and quantitatively, concluding that the diffusion coefficient does not affect the computational results to a great extent, the root mean square error $\varepsilon$ remains lower than $3 \mathrm{~mm}$ for all the flow patterns. Furthermore, it appears that the use of any of the three diffusion coefficients does not permit to improve significantly the computed results (Table 11). Nevertheless, Figure 18 shows that the (b) and (c) diffusion relationships tend to improve the predicted shape of the normal jump for the $C_{21}$ configuration and that formula (a) permits to increase the predicted hydraulic jump thickness for $C_{l}$ configuration.

\section{Conclusion}

In this study, a two-dimensional shallow water equation model Rubar20 is used to compute a large number of observed four branch supercritical junction flows. The model based on a reference set of parameters can predict the observed flow pattern for all the configurations. The main flow structures are accurately located except the normal hydraulic jump in the minor branch for one Type II configuration. On five specific flow configurations for which the water depth field was measured, the typical average error in predicting the water depth field lies between 0.5 and $6 \mathrm{~mm}$ with a root mean square error between 3 and $12 \mathrm{~mm}$ which represents up to $20 \%$ of the measured water depths. The main errors in calculating the water depth fields are related to the prediction of the oblique jump thickness and thus the highest water depth prediction errors concern the flow configurations with two oblique jumps (Type III). Moreover, average error for the flow rate distribution in the downstream branches is equal to about $3 \%$ of the total inflow. Discrepancies can be related to the prediction of the oblique jump angle for the flow configurations in which the oblique jump governs the flow rate distribution (Type II regime 3 and Type III flows).

A sensitivity analysis was performed and no modification of the parameter set could improve all the observed flow configurations but it can be stated that: 
- Using a constant Strickler coefficient similar to the equivalent Strickler coefficient in the upstream branches does not modify the flow pattern greatly, but using the equivalent average Strickler coefficient of the junction, the predicted flow pattern is much affected.

- The flow characteristics at the junction inlet sections are a key parameter governing the flow pattern in the junction.

- By increasing the mesh density, a more accurate flow pattern is computed but in the same time the predicted oblique jump thickness is reduced, which may cause some discrepancy. Moreover the longitudinal mesh density imposed in the branches has a strong influence on the computed flow as it tends to modify the flow characteristics at the upstream sections of the junction.

- Using a diffusion coefficient has only a limited impact on the computed flow but may improve the shape of the predicted flow patterns for some specific configurations such as the $C_{21}$ configuration.

Finally, one can conclude that:

- For engineering purposes, a 2D model is accurate enough to compute the flow inside a crossroad because local obstacles such as cars are likely to create similar level of uncertainty.

- Further research should be concentrated in improving the modelling of the hydraulic jump (thickness and detailed structure).

\section{Acknowledgements}

The research was funded by the French CNRS (SPI-ACI jeune chercheur "Hydraulics in urban areas", 2002), the program ECCO-PNRH 2003 (projectn ${ }^{\circ} 31$ ) and by the French Environment Ministry under the Rio2 Program 'Assessment of the surface flows for an extreme flood in urbanized areas'. Authors gratefully acknowledge P. Dutheil for his technical support.

\section{References}

BEHLKE, C.E. and PRITCHETT, H.D. (1966). "The Design of Supercritical Flow Channel Junctions". Highway Research Record, Transportation Research Board 123.

BEST, J.L. and REID, I. (1984). "Separation zone at open-channel junctions". Journal of Hydraulic Engineering 110(11), 1588-1594.

BOWERS, C.E. (1966). "Studies of open channel junctions". Technical paper, part V of Hydraulic model studies for Whiting Field Naval Air Station, 6(B).

CALENDA, G., CALVANI, L. and MANCINI, C.P. (2003). "Simulation of the great flood of December 1870 in Rome". Water and Maritime Engineering 156(4), 305-312. 
FRENCH, H.R. (1985). “Open-Channel Hydraulics”. Civil Engineering Series. McGraw-Hill. HAGER, W.H. (1989). "Supercritical flow in channel junction". Journal of Hydraulic Engineering 115(5), 595-616.

HUANG, J.C., WEBER, L.J. and LAI, Y.G. (2002). "Three-dimensional numerical study of flows in open-channel junctions". Journal of Hydraulic Engineering 128(3), 268-280.

ISHIGAKI, T., NAKAGAWA, H. and BABA, Y. (2004). "Hydraulic model test and calculation of flood in urban area with underground space". Environmental Hydraulics and Sustainable Water Management-Lee \& Lam (eds): Volume 2, Sustainable Water Management in the Asia-Pacific Region, A.A. Balkema Publishers, 1411-1416.

IPPEN, A. T. (1951). "Mechanics of supercritical flow", 1st paper of High-velocity flow in open channels: a symposium". Transaction, ASCE 116, 268-295.

KHAN, A.A., CADAVID, R. and WANG, S.S.Y. (2000). "Simulation of channel confluence and bifurcation using the CCHE2D model". Water and Maritime Engineering 142, 97-102.

MIGNOT, E. and PAQUIER, A. (2003a). "Impact - Flood propagation case study - The model city flooding experiment". 3rd IMPACT Workshop (EU-funded research project on Investigation of Extreme Flood Processes and Uncertainty), Louvain La Neuve, Belgium. 5-7 November 2003, 23 pages.

MIGNOT, E. and PAQUIER, A. (2003b). "Impact - Flood propagation. Isolated building test case". 3rd IMPACT Workshop (EU-funded research project on Investigation of Extreme Flood Processes and Uncertainty), Louvain La Neuve, Belgium, 5-7 November 2003, 25 pages.

MIGNOT, E. (2005). "Etude expérimentale et numérique de l'inondation d'une zone urbanisée : cas des écoulements dans les carrefours en croix". PhD thesis, Dept. of Mechanics, Civil engineering and Acoustic, Ecole Centrale de Lyon, France (in French).

MIGNOT, E., PAQUIER, A. and HAIDER, S. (2006a). "Modeling floods in a dense urban area using 2D shallow water equations". Journal of Hydrology 327 (1-2), 186-199.

MIGNOT, E., PAQUIER, A. and ISHIGAKI, T., (2006b). "Comparison of numerical and experimental simulations of a flood in a dense urban area". Water Science and Technology 64 (6-7), 65-73.

MIGNOT, E., RIVIÈRE, N., PERKINS, R.J. and PAQUIER, A. (2008). "Flow patterns in a four branches junction with supercritical flow". Submitted to Journal of Hydraulic Engineering.

MORRIS, M. (2005). "IMPACT project - Final technical report". H.R. Wallingford, Wallingford, U. K. http://www.samui.co.uk/impact-project/

NANIA, L.S., GOMEZ, M. and DOLZ, J. (2004). "Experimental study of the dividing flow in steep street crossings". Journal of Hydraulic Research 42(4), 406-412.

NEARY, V.S., SOTIROPOULOS, F. and ODGAARD, A.J. (1999). "Three-dimensional numerical model of lateral-intake inflows". Journal of Hydraulic Engineering, 125(2), 126-140.

PAQUIER, A. (1995). "Modélisation et simulation de la propagation de l'onde de rupture de barrage (Modelling and simulating the propagation of dam-break wave)". PhD Thesis, Université Jean Monnet de Saint Etienne, 215 pages.

PAQUIER, A. (2001). "Rupture de barrage : validation des modèles numériques du Cemagref dans le cadre de CADAM (Dam-break wave: validating Cemagref's numerical models during CADAM)". Ingénieries EAT, 28: 11-21 (In French).

RANGA RAJU, K.G., ASAWA, G.L. and MISHRA, H.K. (2000). "Flow-establishment length in rectangular channels and ducts". Journal of Hydraulic Engineering 126(7), 533-539.

RICE, C.E. (1985). "Open channel junctions with supercritical flow". U.S. Department of Agriculture, 34 pages.

RIVIÈRE, N. and PERKINS, R.J. (2004). "Supercritical flow in channel intersections". Proc. of the 2nd international conference on fluvial hydraulics, Grecco, Carravetta and Della Morte Eds, River Flow 2004, Napoli, Italy, 23-25 June 2004, 1073-1077. 
RIVIÈRE, N., PERKINS, R.J. and MIGNOT, E. (2005). "Flow in a four branch intersection - a comparative study of subcritical and supercritical regimes", Proc. of the XXXIst IAHR Congress, Seoul, Korea, September, 11-16 Septembre 2005, 3553-3561.

ROE, P.L. (1981). "Approximate Riemann solvers, parameter vectors and difference schemes". Journal of Computational Physics 43, 357-372.

SCHMITT, T.G., THOMAS, M. and ETTRICH, N. (2004). "Analysis and modelling of flooding in urban drainage systems". Journal of hydrology, 299: 300-311.

SCHWALT, M. and HAGER, W.H., (1995). "Experiments to supercritical junction flow". Experiments in fluids 18, 429-437.

SHETTAR, A.S. and MURTHY, K.K. (1996). "A numerical study of division of flow in open channels". Journal of Hydraulic Research 34(5), 651-675.

SHUMATE, E.D. and WEBER, L.J. (1998). "Experimental description of combining flows at an open channel junction". Water Resources Engineering. ASCE, Memphis, USA, 16791684.

SOARES FRAZAO, S., MORRIS, M. and ZECH, Y. (2000). (editors) "Concerted action on Dam break modelling: objectives, project report, test cases, meeting proceedings" (CD-ROM). Université Catholique de Louvain, Civil Engineering department, Hydraulics division, Louvain La Neuve, Belgium.

VANLEER, B. (1979). "Towards the ultimate conservative difference scheme. V.A second order sequel to Godunov's method". Journal of computational physics 32, 101-136.

WEBER, L.J., SCHUMATE, E.D. and MAWER, N. (2001). "Experiments on flow at a $90^{\circ}$ openchannel junction". Journal of Hydraulic Engineering 127(5), 340-350.

YEN, B.C. (2002). "Open Channel Flow Resistance". Journal of Hydraulic Engineering 128(1), 20-39. 


\section{Notations}

A =

$\mathrm{b}=$

$\mathrm{d}_{\mathrm{x}}$ and $\mathrm{d}_{\mathrm{y}} \quad=$

$\mathrm{dh} \quad=$

$\overline{d h}$

$\mathrm{E}_{\mathrm{QT}}$

$\mathrm{f}$

$\mathrm{f}_{1}$ and $\mathrm{f}_{2}$

$\mathrm{E}_{\mathrm{QT}}$

$\mathrm{F}_{\mathrm{r}}$

$\mathrm{h}$

$\mathrm{h}_{\mathrm{n}}$

$\mathrm{k}$

$\mathrm{k}_{\mathrm{s}}$

$\mathrm{K}_{\mathrm{s}}$

1

$\mathrm{L}_{\mathrm{c}}$

$\mathrm{m}_{\mathrm{ij}}$

$\mathrm{M}_{\mathrm{i}}$ or $\mathrm{M}_{\mathrm{j}}$

$\mathbf{M}_{1,2,3,4}$

n

$\mathrm{n}_{\mathrm{b}}$

$\mathrm{Q}$

$\mathrm{R}_{\mathrm{e}}$

$\mathrm{R}_{\mathrm{h}}$

$S$

$\mathrm{S}_{\mathrm{x}}$ and $\mathrm{S}_{\mathrm{y}}$

$\mathrm{t}$

$\mathrm{u}$

$\mathrm{u}^{*}$

$\mathrm{V}$

W

$\mathrm{x}, \mathrm{y}$

$\mathrm{z}$

$\mathrm{Z}_{\mathrm{b}}$

$\beta$

$\varepsilon$

$\varepsilon_{\mathrm{ij}}$

$v$

$v_{\mathrm{k}}$

$\Delta \mathrm{t}$

$=$

$=$

$=$ $=\quad$ Cell area

Channel width

Cell dimensions

Difference in water depth

Average water depth difference

Flow rate distribution indicator

Darcy-Weisbach friction coefficient

Fluxes on $\mathrm{x}$ and $\mathrm{y}$ axis of the $1^{\text {st }}$ member of Eqs 2 and 3

Quality indicator

Froude number

$=$ Gravitational acceleration

$=\quad$ Water depth

$=\quad$ Normal water depth

$=$ Dimensionless coefficient (for the diffusion coefficient)

$=\quad$ Roughness length parameter

$=\quad$ Strickler roughness coefficient

$=\quad$ Edge length

$=\quad$ Channel length

$=\quad$ Common edge of cells $\mathrm{i}$ and $\mathrm{j}$

$=\quad$ Cell number $\mathrm{i}$ or $\mathrm{j}$

$=$

$=\quad$ Manning coefficient

Mesh used for calculation

$=\quad$ Number of data

$=$ Discharge

$=\quad$ Reynolds number

$=\quad$ Hydraulic radius

$=$

Second member of Eqs 2 and 3

$=$

$=$

Channel slopes

Time

$=$

$=$

$=$

$=$

$=$

$=$

Velocity component in the $\mathrm{x}$ direction

Friction velocity

Velocity component in the y direction

Triplet of unknowns

Plane axis

Water level

Bottom elevation

$=$

Oblique jump angle
$=$

$=$

$=$

$=$

$=$

Root mean square error

Operator equal to 1 or -1 depending on the orientation of the cell

Diffusion coefficient

Kinematic viscosity

Time step

\section{Subscripts}

C

e

$\mathrm{i}$ or $\mathrm{j}$

$\mathrm{L}$ and $\mathrm{R}$

$\mathrm{M}$

n

S

$\mathrm{T}$

$\mathrm{x}$ and $\mathrm{y}$
$=$

$=$

$=$

$=$

$=$

$=$

$=$

$=$

$=$
Computed

Upstream

Cell number

Left and right

Measured

Time step number

Downstream

Total

Main and minor flow directions 


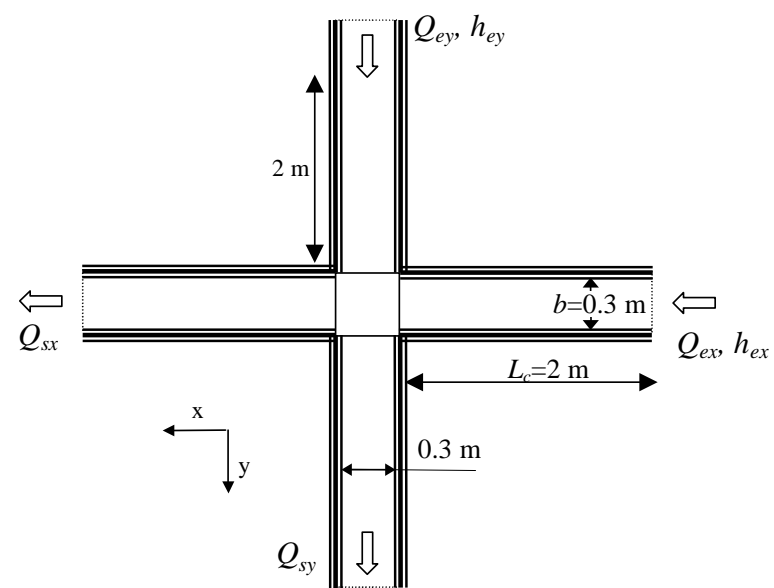

Figure 1: Plan sketch of the experimental set-up in which $Q$ stands for discharge, $h$ for water depth.
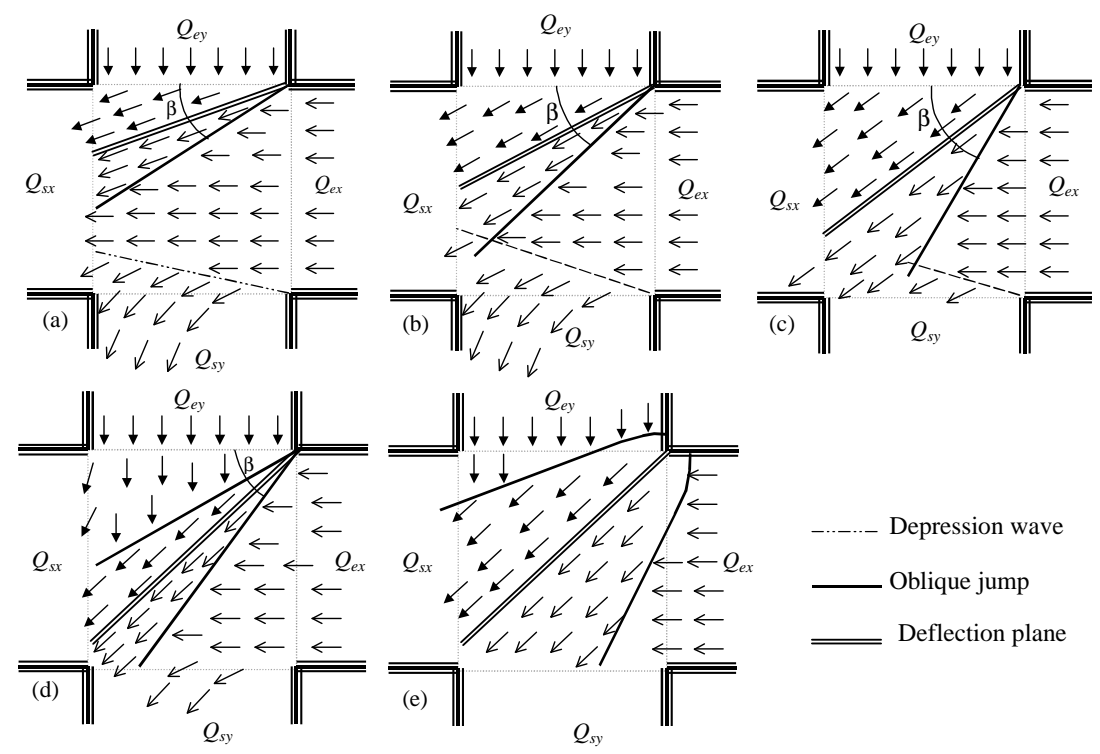

Figure 2: Description of the main flow types observed experimentally (apart from Type I): $(a)=$ Type II regime $1,(b)=$ Type II regime $2,(c)=$ Type II regime $3,(d)=$ Type III, $(e)=$ intermediate Type I - Type III 


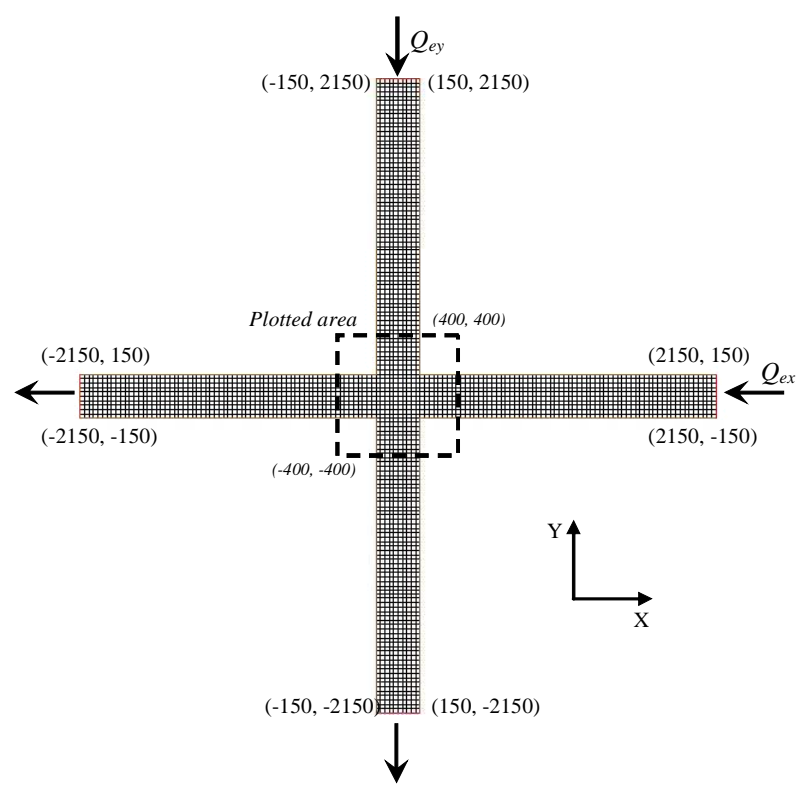

Figure 3: Sketch of the reference numerical mesh used for the computations (coordinates are provided in millimetres)

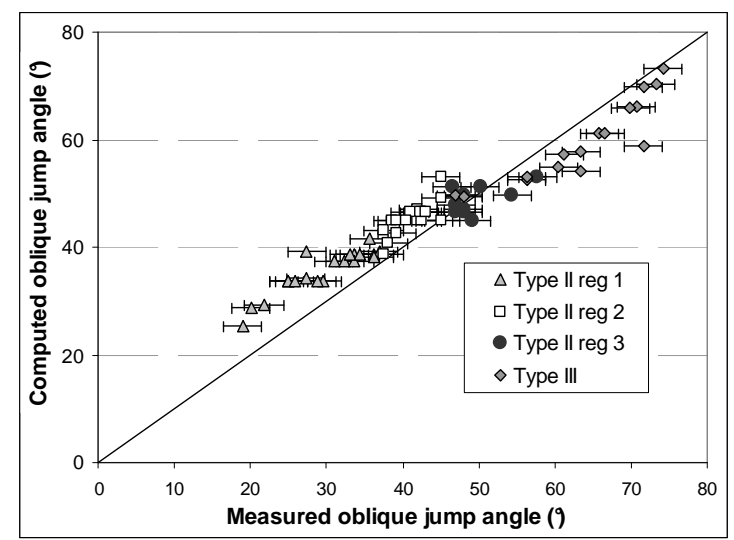

Figure 4: Comparison between measured and computed oblique jump angle for $S_{x}=S_{y}=5 \%$ configurations

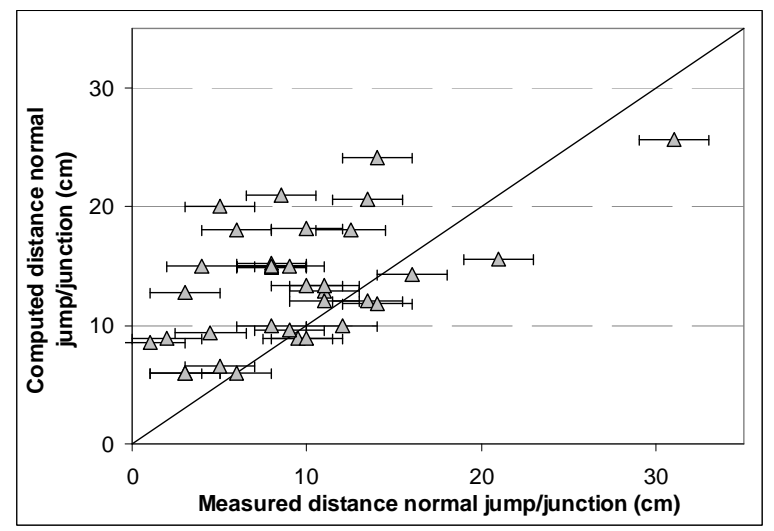

Figure 5: Comparison between measured and computed normal jump locations for $S_{x}=S_{y}=5 \%$ configurations 


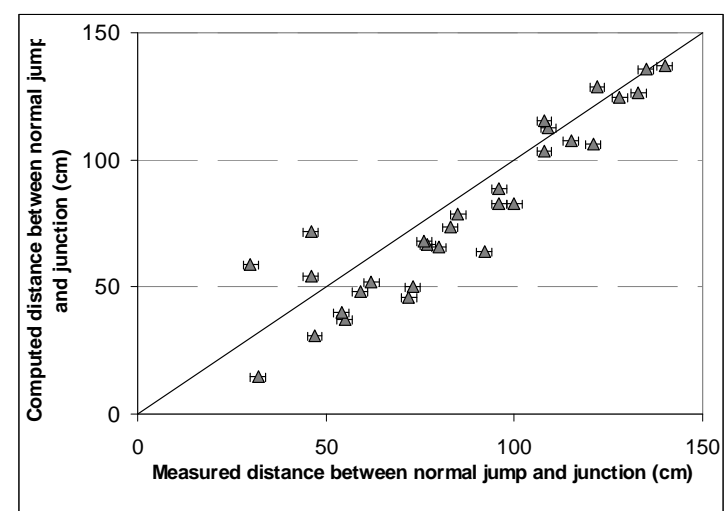

Figure 6: Comparison between measured and computed normal jump locations for $S_{x}=S_{y}=1 \%$ configurations

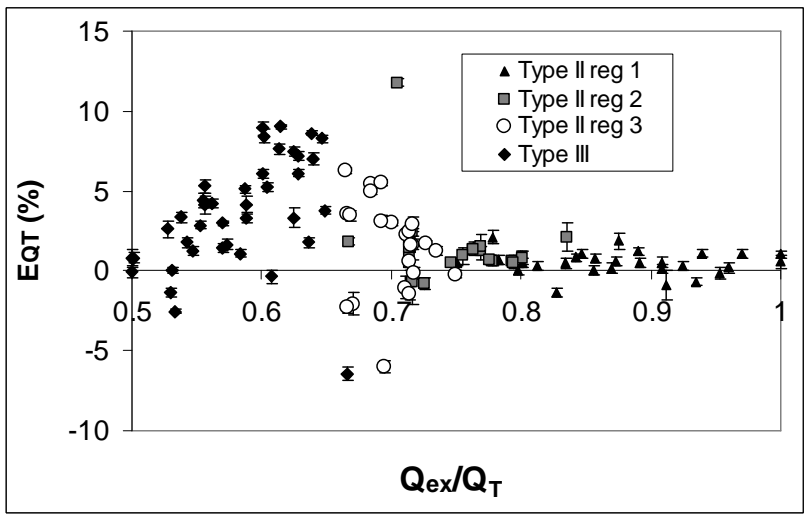

Figure 7: Value of $E_{Q T}$ flow distribution quality indicator for $S_{x}=S_{y}=5 \%$ configurations from Table 2

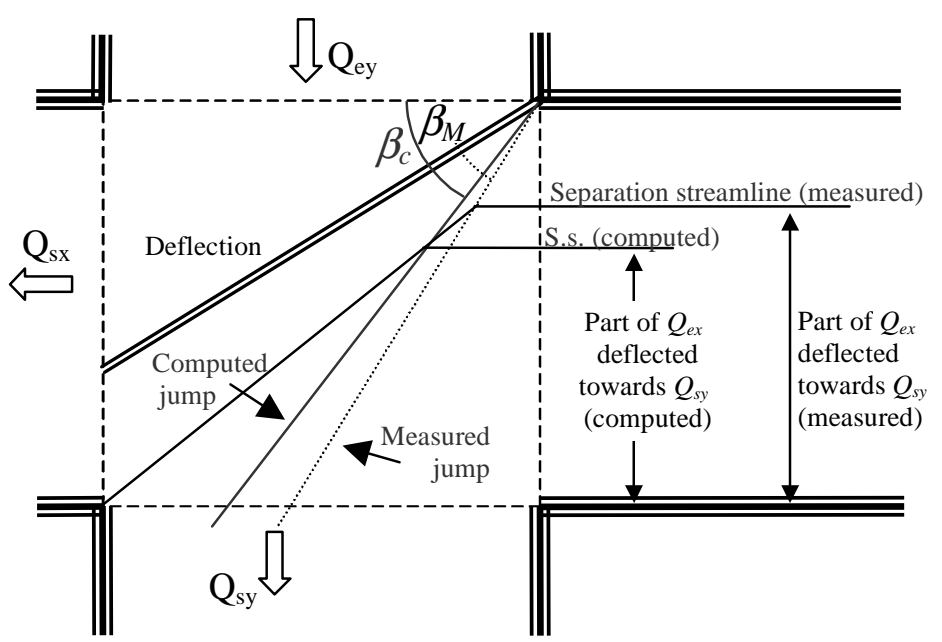

Figure 8: Effect of computed oblique jump angle $\beta_{c}$ underestimation on the flow distribution computation for Type III 


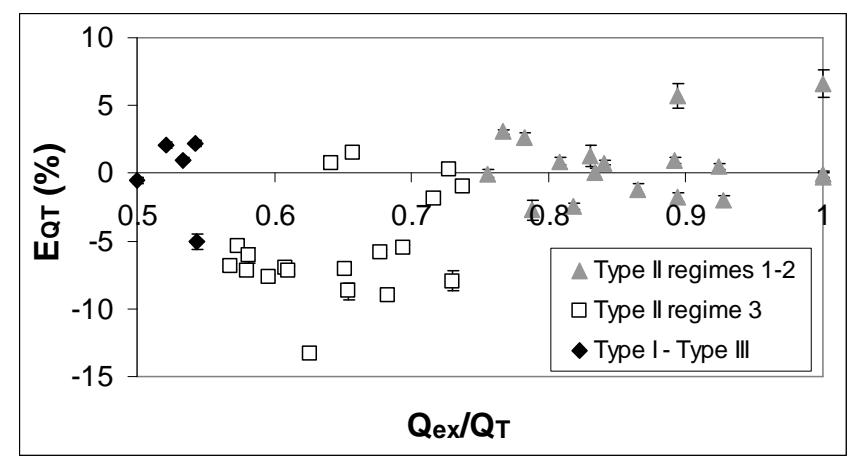

Figure 9: Value of $E_{Q T}$ flow distribution quality indicator for $S_{x}=S_{y}=3 \%$ configurations from Table 2

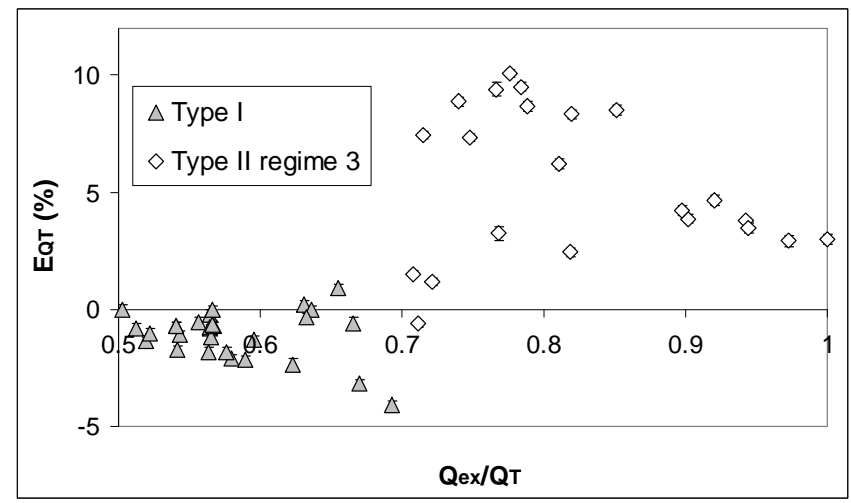

Figure 10: Value of $E_{Q T}$ flow distribution quality indicator for $S_{x}=S_{y}=1 \%$ configurations from Table 2 

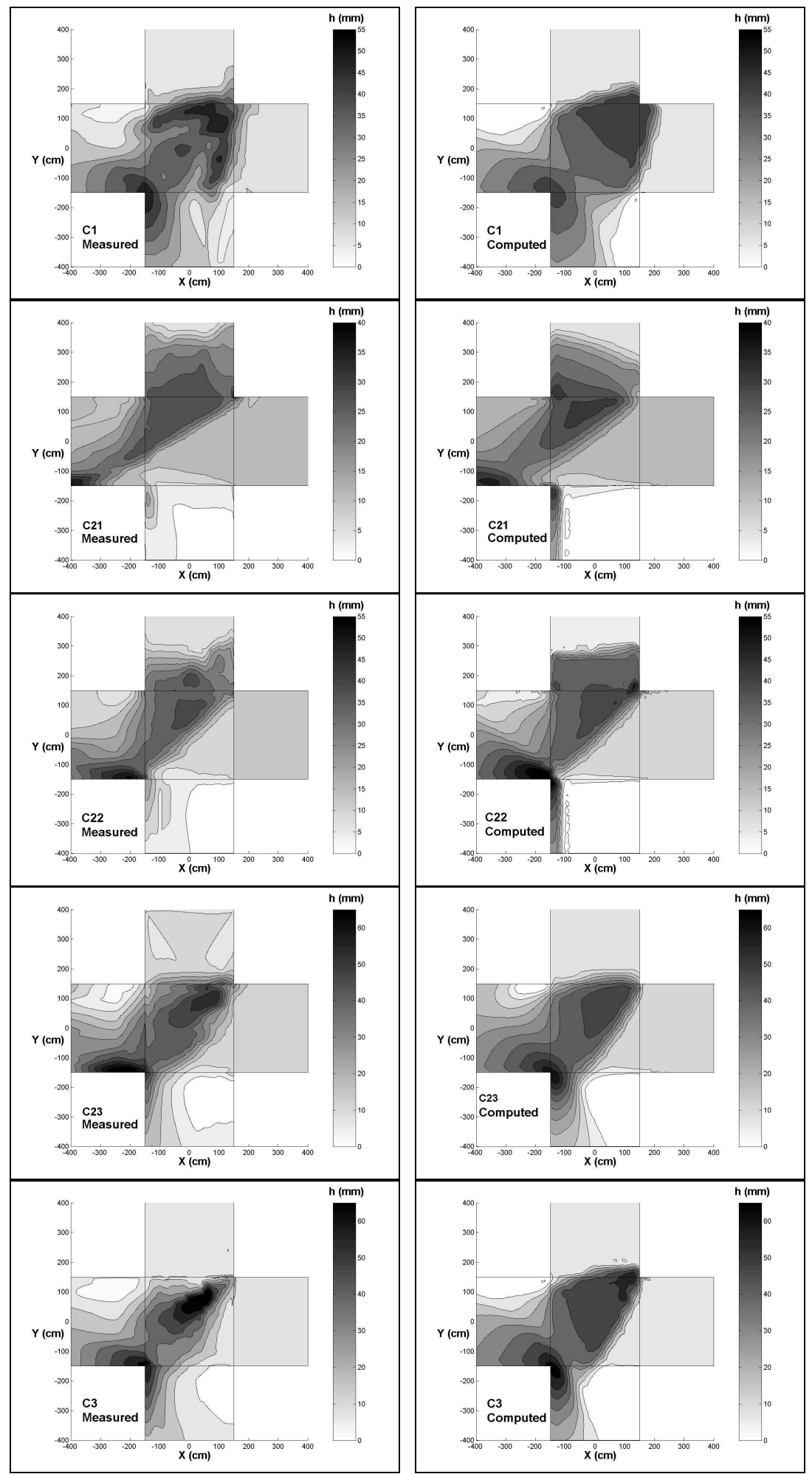

Figure 11: Water depth fields of measured and computed (with the reference parameter set) flow configurations from Table 3 


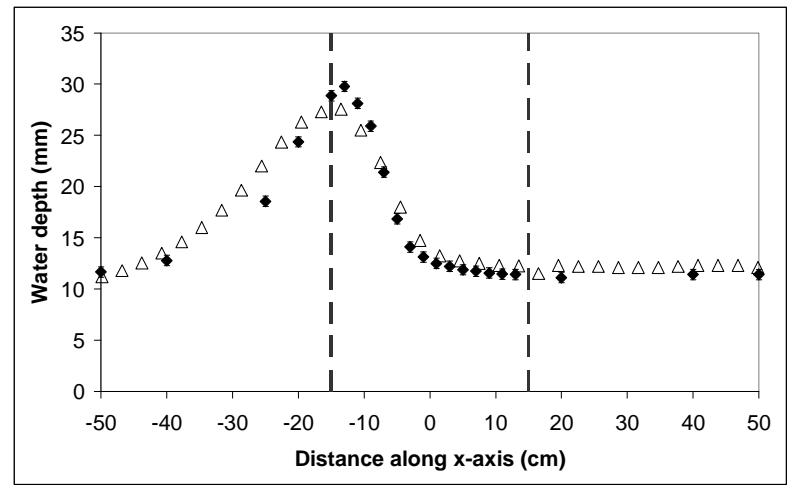

Figure 12: Comparison between computed $(\triangle)$ and measured $(\diamond)$ water depth profiles along $x$ axis for C21 flow configuration (dashed lines show the limits of the junction)
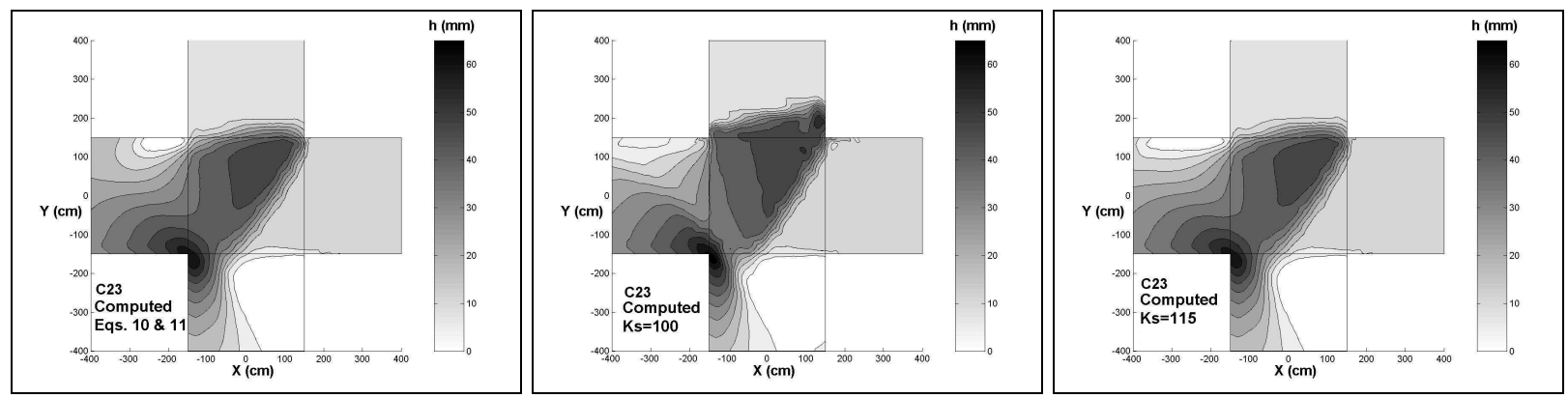

Figure 13: Flow types for $C_{23}$ configuration computed with the three tested friction coefficient formulas

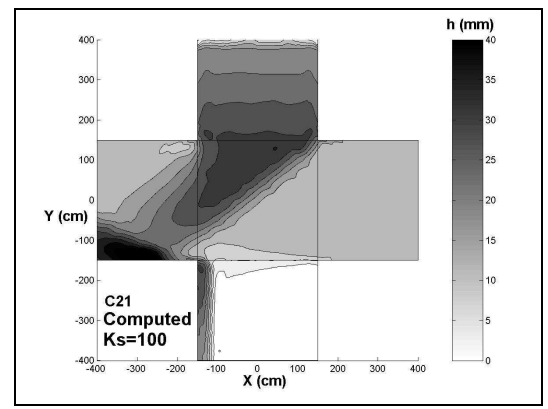

Figure 14: $C_{21}$ flow configuration computed using a constant friction coefficient $K s=100 \mathrm{~m}^{1 / 3} . \mathrm{s}^{-1}$. 

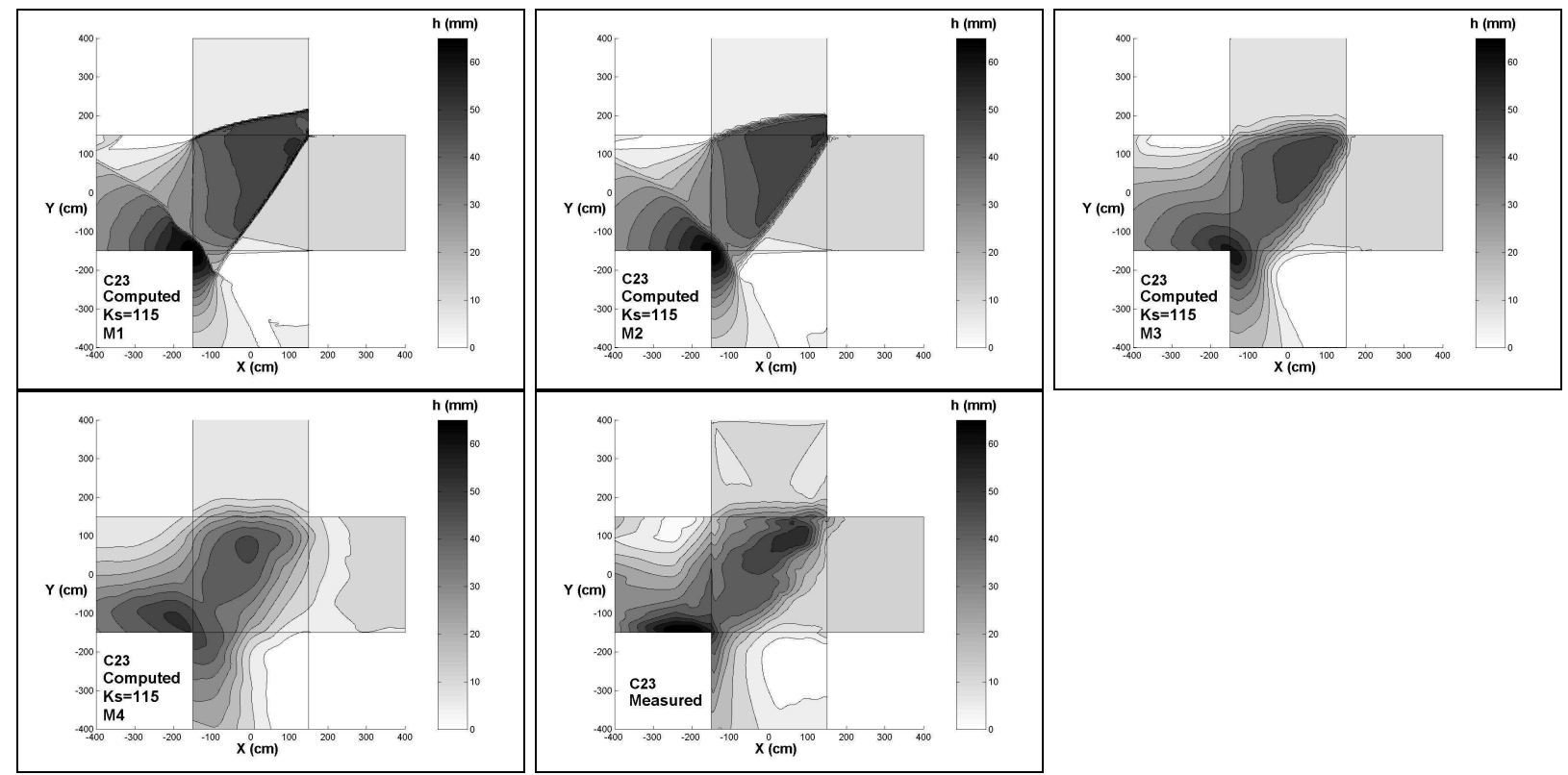

Figure 15: Measured and computed $C_{23}$ flow configurations with the 4 mesh densities from Table 4

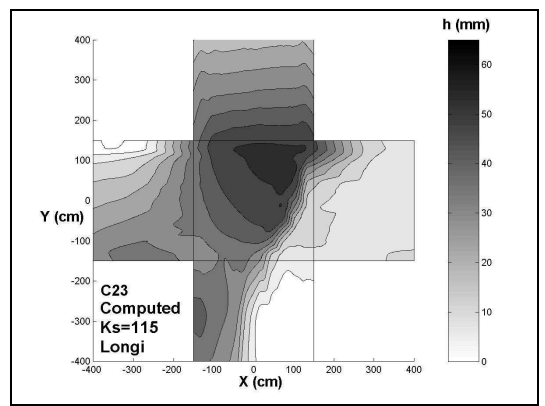

Figure 16: Computed $C_{23}$ flow configuration with the new longitudinal mesh density ("longi")
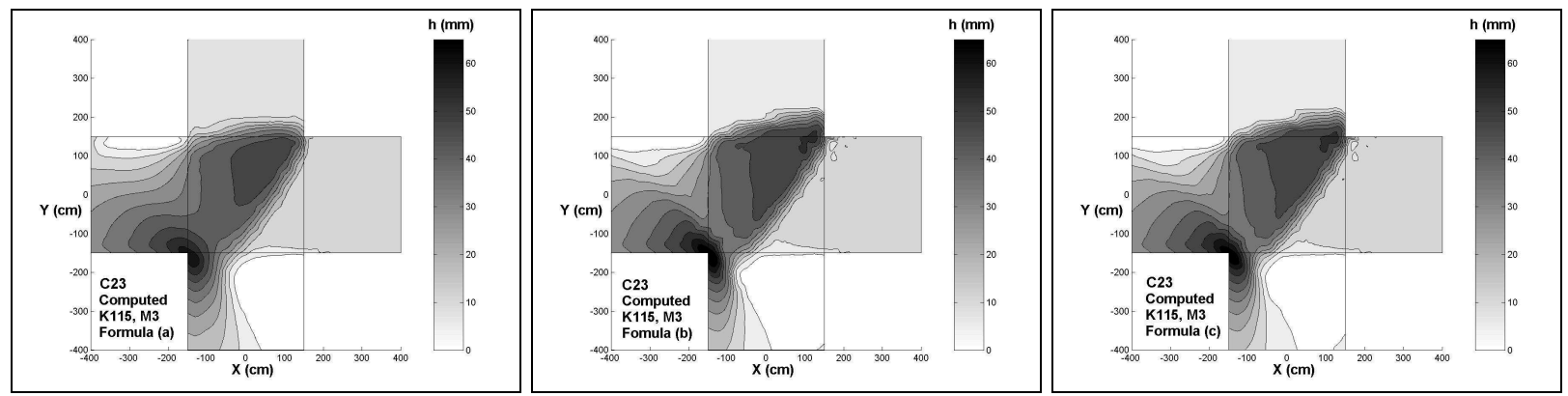

Figure 17: Computed $C_{23}$ flow configuration with the three diffusion coefficient formulas 

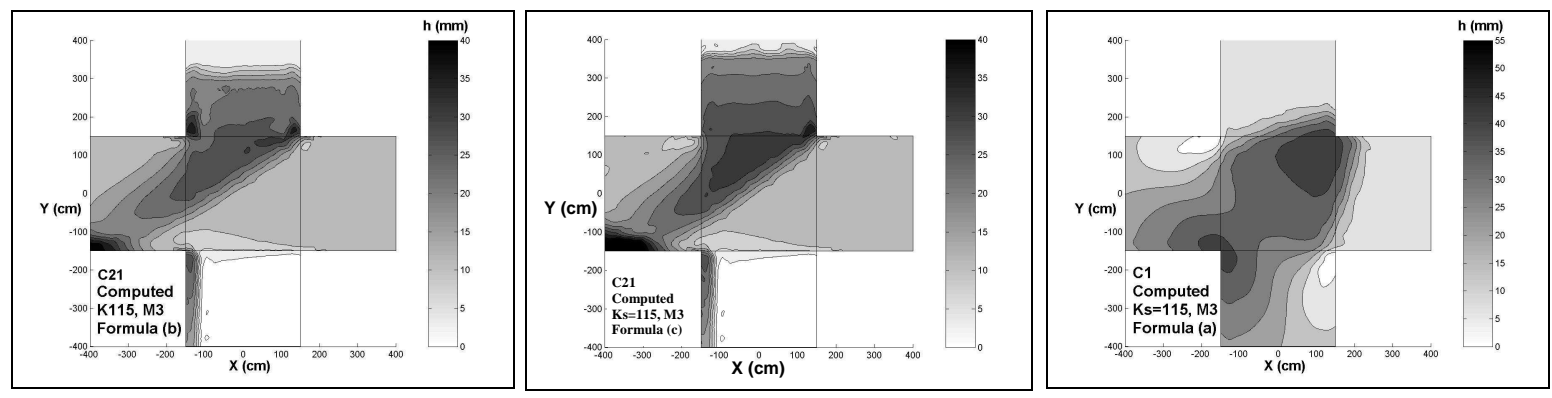

Figure 18: Computed $C_{21}$ flow configuration with diffusion coefficient formulas $(b)$ and $(c)$ and $C_{1}$ flow with formula (a) 
Table $1 \quad$ Range of upstream discharge ratio $Q_{e x} / Q_{T}$ for the various observed flow types.

\begin{tabular}{cccccccc}
\hline & & \multicolumn{5}{c}{$Q_{e x} / Q_{T}$} \\
\cline { 3 - 7 }$S_{x} \& S_{y}$ & $\boldsymbol{F}_{r x} \& \boldsymbol{F}_{r y}$ & Type I & $\begin{array}{c}\text { Type II } \\
\text { regime 1 }\end{array}$ & $\begin{array}{c}\text { Type II } \\
\text { regime 2 }\end{array}$ & $\begin{array}{c}\text { Type II } \\
\text { regime 3 }\end{array}$ & Type III & $\begin{array}{c}\text { Intermediate } \\
\text { Types I-III }\end{array}$ \\
\hline $\mathbf{1} \%$ & {$[\mathbf{1 . 5 - 1 . 8}]$} & {$[0.5-0.7]$} & & & {$[0.7-1]$} & & \\
$\mathbf{3} \%$ & {$[\mathbf{2 . 5 - 3 . 5}]$} & & $\leftarrow$ & {$[0.75-1] \rightarrow$} & {$[0.55-0.75]$} & & {$[0.5-0.55]$} \\
$\mathbf{5} \%$ & {$[3-4.5]$} & & {$[0.75-1]$} & {$[0.66-0.83]$} & {$[0.65-0.75]$} & {$[0.5-0.65]$} & \\
\hline
\end{tabular}

Table 2 Number of flow configurations for which the flow rate distribution was measured. Grey cells correspond to non-observed flow types.

\begin{tabular}{|c|c|c|c|c|c|c|}
\hline$S_{x} \& S_{y}$ & Type I & $\begin{array}{l}\text { Type II } \\
\text { regime } 1\end{array}$ & $\begin{array}{l}\text { Type II } \\
\text { regime } 2\end{array}$ & $\begin{array}{l}\text { Type II } \\
\text { regime } 3\end{array}$ & Type III & $\begin{array}{l}\text { Interm. } \\
\text { Type I-III }\end{array}$ \\
\hline $1 \%$ & 32 & & & 22 & & \\
\hline $3 \%$ & & $\leftarrow \quad 18$ & $\rightarrow$ & 19 & & 5 \\
\hline $5 \%$ & & 29 & 22 & 23 & 39 & \\
\hline
\end{tabular}

Table 3 Flow configurations for which the water depth field was measured

\begin{tabular}{|c|c|c|c|c|c|c|c|}
\hline Case name & $\begin{array}{r}Q_{e x} \\
(l / s)\end{array}$ & $\begin{array}{c}\boldsymbol{h}_{e x} \\
(\mathrm{~cm})\end{array}$ & $\begin{array}{c}Q_{e y} \\
(l / s)\end{array}$ & $\begin{array}{c}\boldsymbol{h}_{e y} \\
(\mathrm{~cm})\end{array}$ & $S_{x} \& S_{y}$ & $\begin{array}{c}\text { Number of } \\
\text { measurement } \\
\text { points in the } \\
\text { junction }\end{array}$ & $\begin{array}{l}\text { Corresponding } \\
\text { flow type }\end{array}$ \\
\hline$C_{1}$ & 3.5 & 1.10 & 3.55 & 1.11 & $3 \%$ & 274 & Intermediate Type I-III \\
\hline$C_{21}$ & 5.11 & 1.15 & 1.01 & 0.44 & $5 \%$ & 260 & Type II regime 1 \\
\hline$C_{22}$ & 5.0 & 1.15 & 2.0 & 0.66 & $5 \%$ & 227 & Type II regime 2 \\
\hline$C_{23}$ & 5.16 & 1.15 & 3.49 & 0.92 & $5 \%$ & 260 & Type II regime 3 \\
\hline$C_{3}$ & 5.02 & 1.15 & 3.99 & 1.00 & $5 \%$ & 253 & Type III \\
\hline
\end{tabular}

Table $4 \quad$ Details of the tested mesh densities

\begin{tabular}{cccc}
\hline Mesh name & $\begin{array}{c}\text { Mesh density } \\
\boldsymbol{d}_{\boldsymbol{x}}=\boldsymbol{d}_{\boldsymbol{v}}=(\mathbf{c m})\end{array}$ & $\begin{array}{c}\text { Number of calculation cells } \\
\text { in each branch section }\end{array}$ & $\begin{array}{c}\text { Number of calculation cells } \\
\text { in the junction }\end{array}$ \\
\hline $\boldsymbol{M 1}$ & 0.5 & 60 & 3600 \\
$\boldsymbol{M} 2$ & 1 & 30 & 900 \\
$\boldsymbol{M 3}$ (Reference) & 3 & 10 & 100 \\
$\boldsymbol{M 4}$ & 10 & 3 & 9 \\
\hline
\end{tabular}

Table 5 Summary of average value of indicator $\overline{A b s\left(E_{Q T}\right)}$ for the three tested slope configurations.

\begin{tabular}{|c|c|c|c|c|c|c|}
\hline$S_{x} \& S_{y}$ & Type I & $\begin{array}{c}\text { Type II } \\
\text { regime } 1\end{array}$ & $\begin{array}{c}\text { Type II } \\
\text { regime } 2\end{array}$ & $\begin{array}{c}\text { Type II } \\
\text { regime } 3\end{array}$ & Type III & $\begin{array}{c}\text { Interm. } \\
\text { Type I-III }\end{array}$ \\
\hline $1 \%$ & $1.28 \%$ & & & $5.42 \%$ & & \\
\hline $3 \%$ & & $\leftarrow \quad 1$. & $\rightarrow$ & $5.78 \%$ & & $2.16 \%$ \\
\hline $5 \%$ & & $0.72 \%$ & $1.62 \%$ & $2.74 \%$ & $4.12 \%$ & \\
\hline
\end{tabular}


Table 6 Average Strickler coefficient computed in the junction and the branches for the 5 flow configurations

\begin{tabular}{cccccc}
\hline Configurations & $\boldsymbol{C}_{\boldsymbol{1}}$ & $\boldsymbol{C}_{21}$ & $\boldsymbol{C}_{22}$ & $\boldsymbol{C}_{23}$ & $\boldsymbol{C}_{\boldsymbol{3}}$ \\
\hline Average $K_{s}$ in the junction $\left(m^{1 / 3} \cdot s^{-1}\right)$ & 103 & 110 & 105 & 105 & 104 \\
Average $K_{s}$ in upstream branches $\left(m^{1 / 3} \cdot s^{-1}\right):$ & 116 & 116.5 & 117 & 118 & 118 \\
\hline
\end{tabular}

Table 7 Comparison between calculation results for the five measured water depth fields

\begin{tabular}{ccccc}
\hline \multirow{2}{*}{ Configurations } & \multicolumn{2}{c}{ Difference $\boldsymbol{K}_{\boldsymbol{s}}=\mathbf{1 1 5}$ / Eqs. 10 \& 11 } & Difference $\boldsymbol{K}_{\boldsymbol{s}}=\mathbf{1 0 0}$ / Eqs. 10 \& 11 \\
\cline { 2 - 5 } & $\overline{d h}(\mathbf{m m})$ & $\boldsymbol{\varepsilon}(\mathbf{m m})$ & $\overline{d h}(\mathbf{m m})$ & $\boldsymbol{\varepsilon}(\mathbf{m m})$ \\
\hline $\boldsymbol{C}_{\boldsymbol{I}}$ & -0.01 & 0.16 & -0.72 & 2.78 \\
$\boldsymbol{C}_{\boldsymbol{2}}$ & -0.84 & 2.08 & 1.25 & 2.24 \\
$\boldsymbol{C}_{\boldsymbol{2}}$ & 0.31 & 0.80 & 2.10 & 3.76 \\
$\boldsymbol{C}_{\boldsymbol{2}}$ & 0.35 & 0.88 & -1.10 & 6.68 \\
$\boldsymbol{C}_{\mathbf{3}}$ & 0.09 & 0.79 & -0.02 & 4.00 \\
\hline
\end{tabular}

Table 8 Average value of discharge distribution quality indicator $\overline{A b s\left(E_{Q T}\right)}$ with the three tested friction coefficients

\begin{tabular}{cccc}
\hline $\boldsymbol{S}_{\boldsymbol{x}} \& \boldsymbol{S}_{\boldsymbol{y}}$ & Eqs. 10 \& 11 & $\boldsymbol{K}_{s}=\mathbf{1 1 5} \boldsymbol{m}^{\mathbf{1 / 3}} \cdot \mathbf{s}^{-1}$ & $\boldsymbol{K}_{s}=\mathbf{1 0 0} \boldsymbol{m}^{\mathbf{1 / 3}} \cdot \mathbf{s}^{-1}$ \\
\hline $\mathbf{1} \%$ & $3.1 \%$ & $3.08 \%$ & $2.23 \%$ \\
$\mathbf{3} \%$ & $3.66 \%$ & $3.64 \%$ & $6.22 \%$ \\
$\mathbf{5} \%$ & $2.48 \%$ & $2.22 \%$ & $3.06 \%$ \\
\hline
\end{tabular}

Table 9 Comparison between the water depth fields computed with the mesh "longi" and with the reference mesh (M3)

\begin{tabular}{ccc}
\hline \multirow{2}{*}{ Configurations } & \multicolumn{3}{c}{ Difference longi / reference case $(\mathbf{M 3})$} \\
\cline { 2 - 3 } & $\overline{d h}(\mathbf{m m})$ & $\boldsymbol{\varepsilon}(\boldsymbol{m m})$ \\
\hline $\boldsymbol{C}_{\boldsymbol{I}}$ & -0.11 & 3.45 \\
$\boldsymbol{C}_{21}$ & 4.4 & 5.7 \\
$\boldsymbol{C}_{22}$ & 4.8 & 8.1 \\
$\boldsymbol{C}_{23}$ & 5.1 & 9.9 \\
$\boldsymbol{C}_{3}$ & 2.3 & 8.6 \\
\hline
\end{tabular}

Table 10 Comparison between the water depth fields computed with the three diffusion coefficient formulas and the set of reference parameters $\left(\nu=0 \mathrm{~m}^{2} \mathrm{~s}^{-1}\right)$

\begin{tabular}{|c|c|c|c|c|c|c|}
\hline \multirow{2}{*}{ Configurations } & \multicolumn{2}{|c|}{$\begin{array}{c}\text { Difference } \\
\text { Formula (a)/reference } \\
\end{array}$} & \multicolumn{2}{|c|}{$\begin{array}{c}\text { Difference } \\
\text { Formula }(\mathbf{b}) / \text { reference } \\
\end{array}$} & \multicolumn{2}{|c|}{$\begin{array}{c}\text { Difference } \\
\text { Formula (c)/reference } \\
\end{array}$} \\
\hline & $\overline{d h}(\mathrm{~mm})$ & $\varepsilon(\mathrm{mm})$ & $\overline{d h}(\mathbf{m m})$ & $\varepsilon(\mathrm{mm})$ & $\overline{d h}$ (mm) & $\varepsilon(\mathrm{mm})$ \\
\hline$C_{1}$ & -0.67 & 1.84 & -0.07 & 0.22 & -0.02 & 0.06 \\
\hline$C_{21}$ & 0.02 & 0.05 & 0.29 & 1.44 & -1.31 & 2.09 \\
\hline$C_{22}$ & 1.44 & 3.11 & -0.06 & 0.39 & -0.01 & 0.16 \\
\hline$C_{23}$ & 0.01 & 0.06 & -0.48 & 3.14 & -0.75 & 3.59 \\
\hline$C_{3}$ & 0.14 & 4.44 & 0.10 & 0.76 & -0.01 & 0.10 \\
\hline
\end{tabular}


Table 11 Statistical comparison between measured and computed water depth fields for the main parameter sets tested

\begin{tabular}{|c|c|c|c|c|c|c|c|c|c|c|}
\hline \multirow{4}{*}{$\begin{array}{c} \\
\begin{array}{c}\text { Friction } \\
\text { coef. }\end{array} \\
\text { Mesh }\end{array}$} & \multirow{4}{*}{$\begin{array}{c}\text { Ref } \\
\begin{array}{c}E q . \\
10 \& 11\end{array} \\
M 3\end{array}$} & \multirow{2}{*}{\multicolumn{5}{|c|}{$\begin{array}{c}\text { Use of } \\
\text { constant friction coefficient }\end{array}$}} & \multirow{4}{*}{$\begin{array}{c}\begin{array}{c}\text { Longitudinal } \\
\text { mesh }\end{array} \\
K_{s}=115 \mathrm{~m}^{1 / 3} \cdot \mathrm{s}^{-1} \\
\mathrm{M} 3\end{array}$} & \multicolumn{3}{|c|}{ Diffusion formula } \\
\hline & & & & & & & & (a) & (b) & (c) \\
\hline & & \multirow{2}{*}{$\begin{array}{c}\begin{array}{c}K_{s}= \\
100 m^{1 / 3} \cdot s^{-1}\end{array} \\
M 3\end{array}$} & \multicolumn{4}{|c|}{$K_{s}=115 m^{l / 3} \cdot s^{-1}$} & & \multicolumn{3}{|c|}{$K_{s}=115 \mathrm{~m}^{l / 3} \cdot \mathrm{s}^{-1}$} \\
\hline & & & M1 & M2 & M3 & M4 & & M3 & M3 & M3 \\
\hline \multicolumn{11}{|l|}{$\overline{d h}(\boldsymbol{m m})$} \\
\hline$C_{1}$ & 0.78 & 0.05 & 1.12 & 1.02 & 0.77 & -2.99 & 1.55 & 0.20 & 0.71 & 0.75 \\
\hline$C_{21}$ & 0.96 & 2.21 & 1.07 & 0.00 & 0.12 & -0.21 & 4.32 & 1.27 & 1.55 & 0.10 \\
\hline$c_{22}$ & 1.13 & 2.82 & 3.18 & 1.02 & 1.40 & 0.81 & 5.67 & 2.57 & 1.31 & 1.37 \\
\hline$C_{23}$ & 0.63 & -0.47 & -0.04 & 0.67 & 0.98 & -2.78 & 6.67 & 0.99 & 0.92 & 0.65 \\
\hline$C_{3}$ & 5.73 & 5.71 & 6.84 & 5.64 & 5.81 & 2.24 & 8.81 & 5.99 & 5.92 & 5.80 \\
\hline \multicolumn{11}{|l|}{$\varepsilon(m m)$} \\
\hline$C_{1}$ & 5.22 & 6.07 & 6.02 & 5.98 & 5.24 & 7.76 & 7.01 & 5.38 & 5.20 & 5.24 \\
\hline$C_{21}$ & 2.92 & 3.32 & 4.47 & 2.86 & 1.82 & 4.65 & 5.51 & 3.07 & 2.50 & 1.83 \\
\hline$C_{22}$ & 3.40 & 5.41 & 7.36 & 5.46 & 3.77 & 6.16 & 8.93 & 5.44 & 3.76 & 3.71 \\
\hline$C_{23}$ & 4.92 & 7.17 & 8.32 & 7.20 & 4.89 & 8.86 & 11.63 & 4.88 & 5.52 & 5.42 \\
\hline$c_{3}$ & 11.99 & 12.95 & 13.20 & 13.55 & 12.27 & 11.02 & 17.02 & 11.25 & 12.21 & 12.22 \\
\hline
\end{tabular}

